Xie, Y., et al., 2022, Groundwater age persistence in topography-driven groundwater flow over paleohydrogeologic time scales: Geology, v. 50, https://doi.org/10.1130/G49842.1

Supplementary material for

\title{
Groundwater age persistence in topography-driven groundwater flow over paleohydrogeologic time scales
}

Yueqing Xie ${ }^{1}$, Andrew J. Love ${ }^{2}$, Craig T. Simmons ${ }^{2}$, Adrian Costar ${ }^{3}$, and Jichun $\mathrm{Wu}^{1}$

${ }^{1}$ Key Laboratory of Surficial Geochemistry of the Ministry of Education, School of Earth Sciences and Engineering, Nanjing University, Nanjing, China

${ }^{2}$ National Centre for Groundwater Research and Training \& College of Science and Engineering, Flinders University, Adelaide, Australia

${ }^{3}$ Water Resources Division, Department of Environment, Parks \& Water Security, Northern Territory Government, Palmerston, Australia 


\section{Governing equations for simulating variably saturated groundwater flow}

In this study, groundwater hydrodynamics were simulated using the Richard's equation because of its capability of dealing with variably saturated flow (Diersch, 2013). Because of the gravity effect, an initially undulating water table would start to flatten out once the climate transitioned to the Holocene. This would lead to the development of the unsaturated zone and time-varying discharge zones. The Richards' equation was appropriate to simulate such a dynamic process between the land surface and the aquifer. The equation is given by

$$
\phi \frac{\partial S_{w}}{\partial t}+\nabla \cdot \mathbf{q}=Q
$$

where $\phi$ is the porosity [dimensionless], $S_{w}$ is the water saturation [dimensionless], $\mathbf{q}$ is the Darcy flux vector $\left[\mathrm{L} \mathrm{T}^{-1}\right], Q$ is the fluid source/sink term $\left[\mathrm{T}^{-1}\right], t$ is the time $[\mathrm{T}] . \mathbf{q}$ takes the form of

$$
\mathbf{q}=-\mathbf{K} \cdot k_{r} \nabla(\psi+z)
$$

where $\mathbf{K}$ is the hydraulic conductivity tensor $\left[\mathrm{L} \mathrm{T}^{-1}\right], k_{r}$ represents the relative permeability of the medium [dimensionless], $\psi$ and $z$ are pressure head and elevation head, respectively [L].

The relationships between $\psi$ and $S_{w}$, and between $k_{r}$ and $S_{w}$ are established using the van Genuchten soil retention functions, given by

$$
\begin{array}{ll}
S_{w}=S_{w r}+\left(1-S_{w r}\right)\left[1+|\alpha \psi|^{\beta}\right]^{-\left(1-\frac{1}{\beta}\right)} & \text { for } \psi<0 \\
S_{w}=1 & \text { for } \psi \geq 0 \\
k_{r}=S_{e}^{1 / 2}\left[1-\left(1-S_{e}^{1 / v}\right)^{v}\right]^{2} & \\
v=1-\frac{1}{\beta}, \beta>1 & \\
S_{e}=\frac{S_{w}-S_{w r}}{1-S_{w r}} &
\end{array}
$$

where $S_{w r}$ is the residual water saturation [dimensionless], $\alpha$ and $\beta$ are the inverse of the 
air-entry pressure head $\left[\mathrm{L}^{-1}\right]$ and the pore-size distribution index [dimensionless], respectively.

\section{Governing equation for simulating mean groundwater age transport}

In this study, we simulated groundwater age distributions using the mean age approach (Goode, 1996; Diersch, 2013). Different water particles will remain in a groundwater system for different times since their entry. These different times are termed as groundwater age, which is usually characterized by age tracers such as ${ }^{14} \mathrm{C}$. As a groundwater sample contains a large number of water particles, mean groundwater age is usually used in analyses. The Goode (1996) approach simulates the mean groundwater age of water particles using the advection-dispersion equation for simulating solute transport. Unlike solute transport, the simulated mean age increases at the rate of 1 year per year along the flow paths. The transport equation is given by

$$
\phi \frac{\partial\langle A\rangle}{\partial t}=-\nabla \cdot\langle A\rangle \mathbf{q}+\nabla \cdot(\mathbf{D} \cdot \nabla\langle A\rangle)+\phi+Q_{A}
$$

where $\langle A\rangle$ is the mean groundwater age $[\mathrm{T}], \mathbf{D}$ is the tensor of the hydrodynamic dispersion $\left[\mathrm{L}^{2}\right.$

$\mathrm{T}^{-1}$ ], $Q_{A}$ is the source/sink term of the age mass [dimensionless]. The first two terms on the right-hand side of Equation (8) represent the transport of the age mass due to advection and dispersion, respectively. The third term is the age increase of the age mass per unit time within the aquifer. The last term represents the exchange of the age mass with the outside of the aquifer.

\section{Model conceptualization}

In this study, a classic model introduced by Tóth (1963) was adapted to conduct numerical experiments (Figure S1). This model was employed because it provides the most general conceptual formulation for groundwater flow systems available in contemporary groundwater 
science. Tóth (1963) introduced the theory of topography-driven groundwater flow at different spatial scales using a sinusoidal function as a fixed model boundary condition to simulate groundwater flow in undulating hill-valley terrains, and found that groundwater flowpaths from recharge to discharge zones may vary over different horizontal and vertical length scales, resulting in the development of independent or nested flow systems. This theory has been extensively studied and widely accepted since then (e.g., Tóth, 2009; Robinson and Love, 2013). The classic Tóth formulation is steady state and hydraulic only.

One of the original geometries used in the Tóth model is rectangular in shape with the aquifer thickness of $1000 \mathrm{~m}$. The model was assigned with a fixed but spatially-varying hydraulic head boundary conditions on the top surface and no-flow boundary conditions on all the other sides, respectively. The spatially-varying head on the top surface represents an undulating water table and is described by the following formula,

$$
z=z_{0}+x \tan \tau+a \sin \left(\frac{2 \pi x}{\lambda \cos \tau}\right) / \cos \tau
$$

where $z_{0}$ is the thickness of the aquifer on the left-hand side [L], $x$ is the distance from the left-hand side [L], $a$ is the amplitude of the sine wave [L], $\lambda$ is the wavelength [L], $\tan \tau$ is the regional hydraulic gradient [dimensionless]. The spatially-varying head is also depicted graphically in Figure S1. This water table is considered to be a subdued form of the topography.

As the climate was wetter in the Pleistocene, it is believed that the recharge was much greater than today and so the water table was likely to represent a subdued mirror coincided with the topography (Rousseau-Gueutin et al., 2013; Voss and Soliman, 2014). To simulate the changes in 
water table undulation in response to historical climate change, the top surface of the original model was modified to reflect more realistic conditions using Equation (9) as shown in Figure S1. This modification will allow for time-varying discharge and variably saturated flow (Figure 1 and S1). Note that the units used by Tóth (1963) are in feet. We kept the size of the aquifer model unchanged because the hydraulics in this problem has been extensively studied over the past several decades (Tóth, 2009, and references therin).

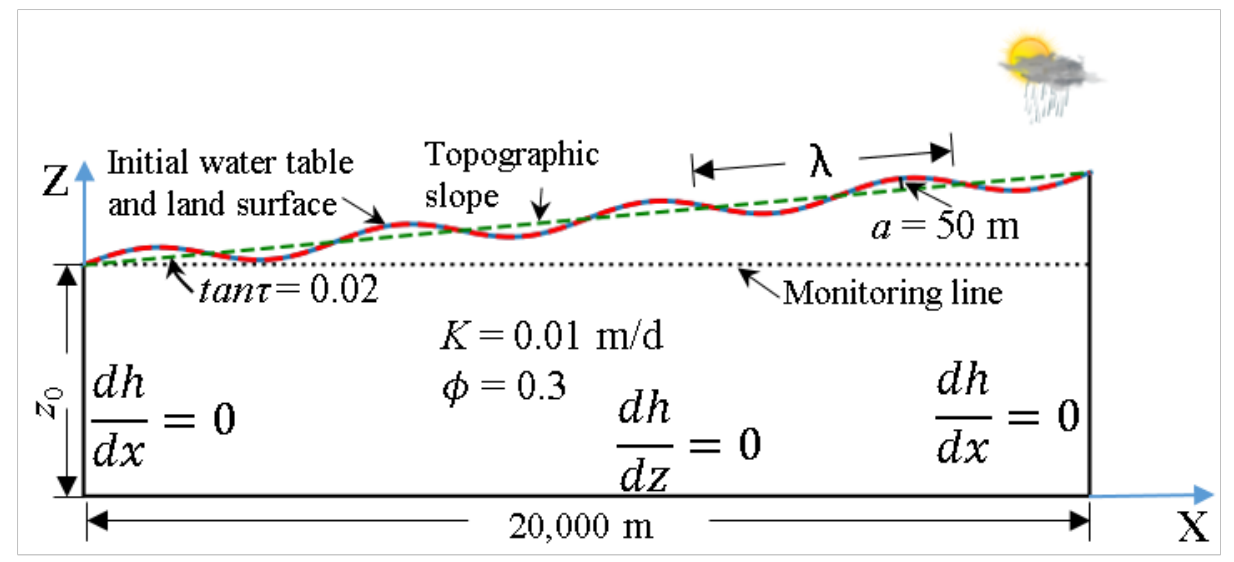

Figure S1. Schematic diagram of the conceptual model and initial and boundary conditions for the base case used in this study. The model length is fixed at $20,000 \mathrm{~m}$. $\mathrm{z}_{0}$ equals $1000 \mathrm{~m}$. The model surface is represented by a tilting sinusoidal wave described by Equation (9). The top surface is the land surface and also assumed to be the initial water table.

Hydraulic parameters are required for performing flow simulation. In this study, we assumed that the model is representative of sandy aquifers with hydraulic conductivity of $0.01 \mathrm{~m} / \mathrm{d}$ and porosity of 0.3 (Freeze and Cherry, 1979). The van Genuchten soil retention curve parameters $\alpha$ and $\beta$ for sand were derived from Carsel and Parrish (1988) and are listed in Table S1. Dispersivity values are also needed to describe hydrodynamic dispersion as water particles navigate around solid 
particles. The longitudinal dispersivity was chosen at $100 \mathrm{~m}$ due to the large aquifer length based on Schulze-Makuch (2005) and the wide spectrum of particle transport routes. The transverse dispersivity was one tenth of the longitudinal dispersivity as commonly used. The modified model serves as a control benchmark for our analysis. Figure S1 and Table S1 show the model setup and relevant parameters, respectively.

Table S1. Parameters used in the base case.

\begin{tabular}{|l|l|l|}
\hline Parameter & Unit & Value \\
\hline Saturated hydraulic conductivity K & $\mathrm{m} / \mathrm{d}$ & 0.01 \\
\hline Porosity $\phi$ & - & 0.3 \\
\hline van Genuchten parameter $\alpha$ & $1 / \mathrm{m}$ & 14 \\
\hline van Genuchten parameter $\beta$ & - & 2.8 \\
\hline Longitudinal dispersivity $\mathrm{D}_{\mathrm{L}}$ & $\mathrm{m}$ & 100 \\
\hline Transverse dispersivity $\mathrm{D}_{\mathrm{T}}$ & $\mathrm{m}$ & 10 \\
\hline Aquifer thickness $z_{0}$ & $\mathrm{~m}$ & 1,000 \\
\hline Regional hydraulic gradient $\tan \tau$ & - & 0.02 \\
\hline topographic amplitude $a$ & $\mathrm{~m}$ & 50 \\
\hline
\end{tabular}

\section{Groundwater flow and age simulations}

To simulate groundwater flow, the modified model was run in steady state at first and then in transient mode using the groundwater simulator FEFLOW (Diersch, 2013). The transient modelling was conducted to examine the direct impact of the Pleistocene-Holocene climate transition on the transient genesis and evolution of the subsequent groundwater system. The steady state flow field was adopted as the initial condition for the transient case. In the transient modeling, 
we compared the hydraulic head of each top boundary node to its elevation at every time step and assigned a seepage boundary condition if the head is greater than the elevation at a node (outward flow), or a zero flux boundary condition otherwise. All the other sides were specified with no-flow boundary conditions, same as the steady state case.

The simulation of groundwater age was also performed in two steps in the same manner as the simulation of groundwater flow, i.e., steady state simulation followed by transient simulation. The steady state age distribution was used as the initial condition for the transient case. By default, water particles are aged at zero the moment they enter a groundwater system through the recharge boundary. The age mass increases at a rate of 1 year per year as the water particles flows through the system until reaching the discharge boundary. In both steady state and transient cases, a mean age of zero will be specified to the boundary nodes when incoming flow occurs. Zero concentration-gradient is specified to the boundary nodes internally when outgoing flow occurs. Time steps were variable, determined by FEFLOW according numerical errors in previous steps.

Although the reduction in recharge would usually be a smooth function of time, here we chose to use a step change in our experiments (i.e., no recharge for the total Holocene period) because of very limited information on the actual temporal change in recharge that occurred in the transition period (Table 1 in the main text). The models in this study were run for 10,000 years with time zero assumed to be the beginning of the Holocene. 


\section{Model validation}

The numerical solutions of the modified model were compared to the analytical solution of the classic model visually. Figure S2 shows that the numerical solution of the model was the same as its analytical solution (compare S2 (a) relative to (b)). After modifying the elevation of top surface to coincide with the spatial head variation, the head and streamline solutions remain almost unchanged on the left half domain but differ slightly from the original model in the lower part of the right half domain (compare S2 (c) relative to (a) and (b) in Figure S2). The comparison indicates the modified model is appropriate to perform numerical experiments for benchmarking potential long-term impacts of the Pleistocene-Holocene climatic transition on groundwater systems.

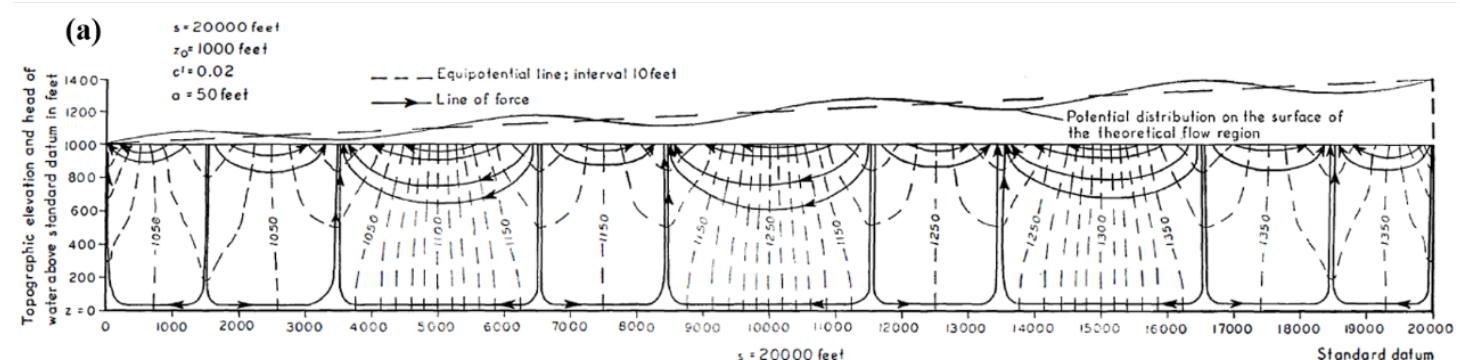

(b)

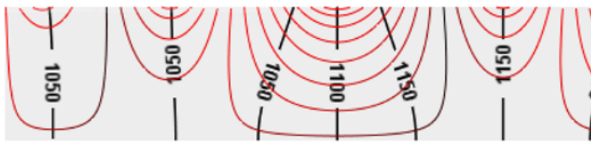

(c)

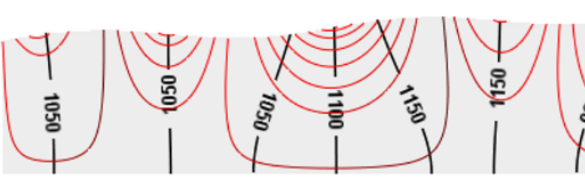

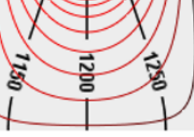

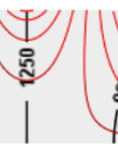

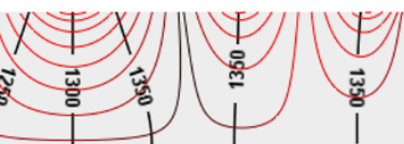

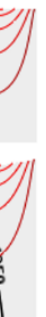

Figure S2. Comparison of hydraulic head (Black dashed lines in (a) and black solid lines in (b) and (c)) and streamline solutions (Arrow lines in (a) and red lines in (b) and (c)): (a) the analytical solution of the classic model presented in Tóth et al. (1963); (b) the numerical solution of the classic model produced in FEFLOW with the same model setup as (a); and (c) the numerical solution of the modified model produced in FEFLOW with the same model setup as (a) except the 
solution is mapped to an undulating top surface.

\section{Modelling results}

Figure S3 (Model 1) to Figure S6 (Model 4) show detailed groundwater flow field and age pattern at different times after recharge cessation. Main parameters are shown in Table S2. The results at 1 year show different age patterns, indicating the important role of aquifer geometry in controlling steady sate age patterns. The comparison in the results between times demonstrate that groundwater flow changes rapidly in response to climate change but the response of age patterns is significantly delayed. The phenomena suggest that the geometry plays little role in affecting the transience of age patterns.

Table S2. Parameters that are modified for sensitivity analysis for Figure 2 in the main text and

Figure S7 in this document.

\begin{tabular}{|c|c|c|c|c|c|c|}
\hline Model & $\begin{array}{c}\text { Aquifer } \\
\text { Thickness } \\
z_{0}(\mathrm{~m})\end{array}$ & $\begin{array}{c}\text { topographic } \\
\text { amplitude } \\
a(\mathrm{~m})\end{array}$ & $\begin{array}{c}\text { Regional } \\
\text { gradient } \\
\text { tan } \tau\end{array}$ & $\begin{array}{c}\text { hydraulic } \\
\text { conductivity } \\
\mathrm{K}(\mathrm{m} / \mathrm{d})\end{array}$ & $\begin{array}{c}\text { Vertical K } \\
\text { distribution }\end{array}$ & $\begin{array}{c}\text { longitudinal } \\
\text { dispersivity } \\
\mathrm{D}_{\mathrm{L}}(\mathrm{m})\end{array}$ \\
\hline Base case & 1000 & 50 & 0.02 & 0.01 & constant & 100 \\
\hline Model 1 & 1000 & 5 & 0.02 & 0.01 & constant & 100 \\
\hline Model 2 & 1000 & 5 & 0.002 & 0.01 & constant & 100 \\
\hline Model 3 & 100 & 5 & 0.002 & 0.01 & constant & 100 \\
\hline Model 4 & 10000 & 50 & 0.02 & 0.01 & constant & 100 \\
\hline Model 5 & 1000 & 50 & 0.02 & 0.1 & constant & 100 \\
\hline Model 6 & 1000 & 50 & 0.02 & 0.01 & exponential & 100 \\
\hline
\end{tabular}




\begin{tabular}{|l|c|c|c|c|c|c|}
\hline Model 7 & 1000 & 50 & 0.02 & 0.01 & constant & 10 \\
\hline
\end{tabular}

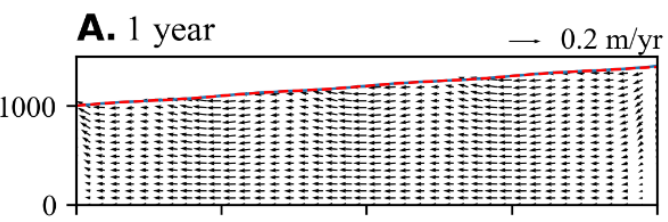

B. 100 years



$$
\text { C. } 1000 \text { years }
$$

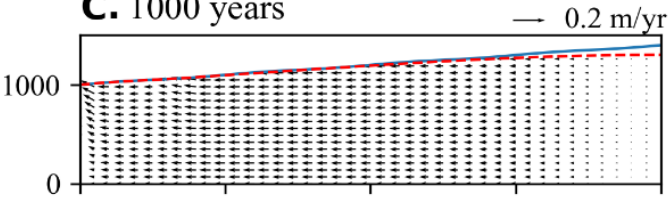

D. 10000 years

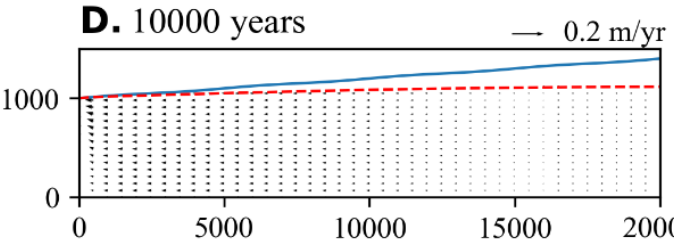

E. 1 year

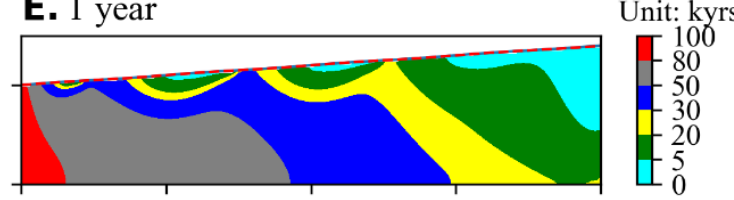

F. 100 years



G. 1000 years

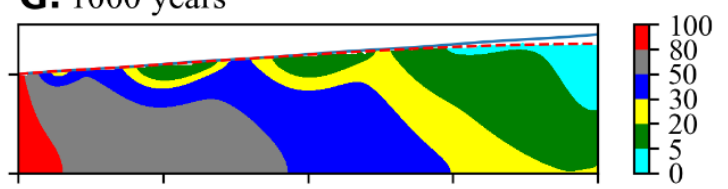

H. 10000 years

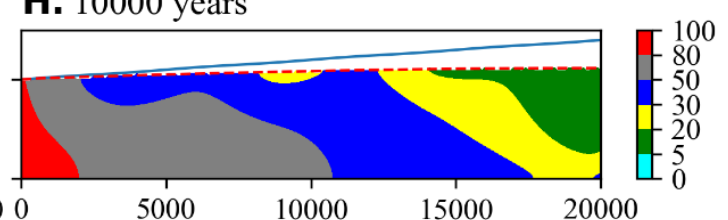

Figure S3. Temporal variation in groundwater flow and groundwater age corresponding to Figure $2 \mathrm{~B} 1$ and $2 \mathrm{~B} 2$, respectively. The aquifer setting is the same as the base case except that the topographic amplitude $a$ was changed from $50 \mathrm{~m}$ to $5 \mathrm{~m}$.
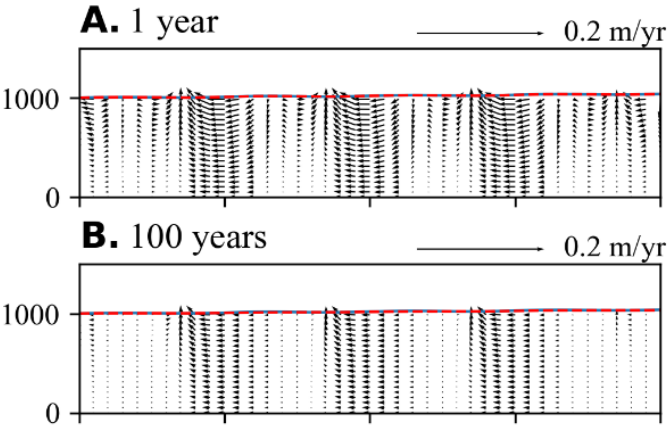

C. 1000 years

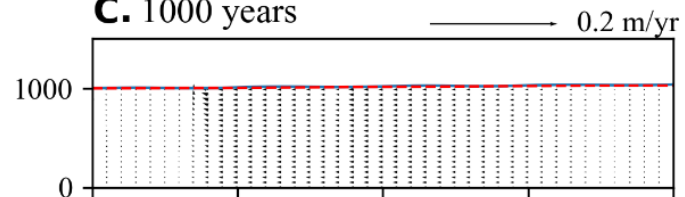

D. 10000 years

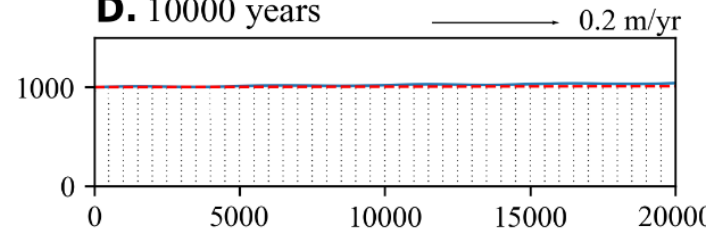

E. 1 year

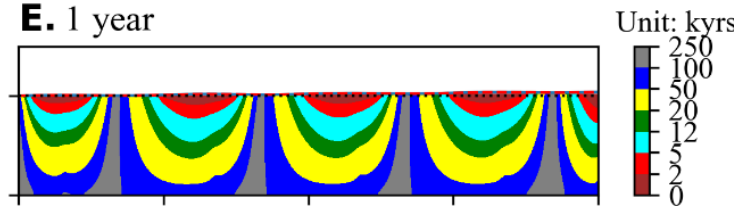

F. 100 years

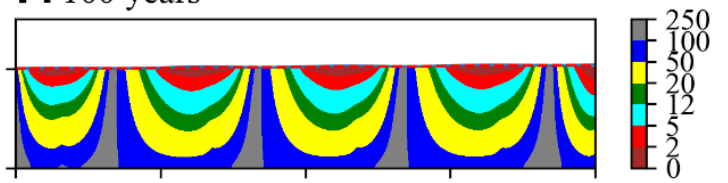

G. 1000 years

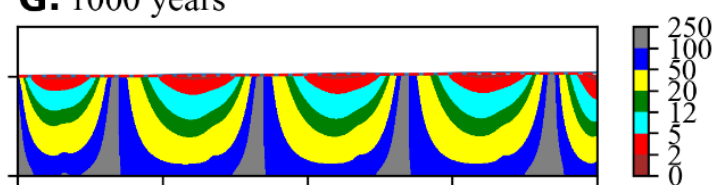

H. 10000 years

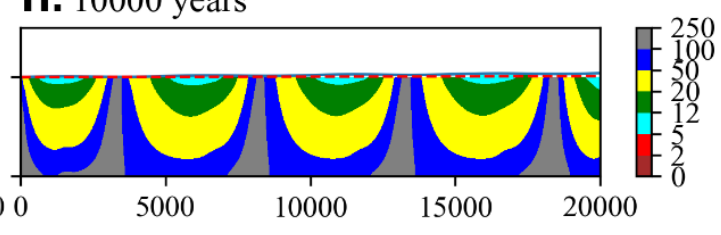


Figure S4. Temporal variation in groundwater flow and groundwater age corresponding to Figure $2 \mathrm{C} 1$ and $2 \mathrm{C} 2$, respectively. The aquifer setting is the same as the base case except that the topographic amplitude $a$ was changed from $50 \mathrm{~m}$ to $5 \mathrm{~m}$ and the slope tan $\tau$ was changed from 0.02 to 0.002 .
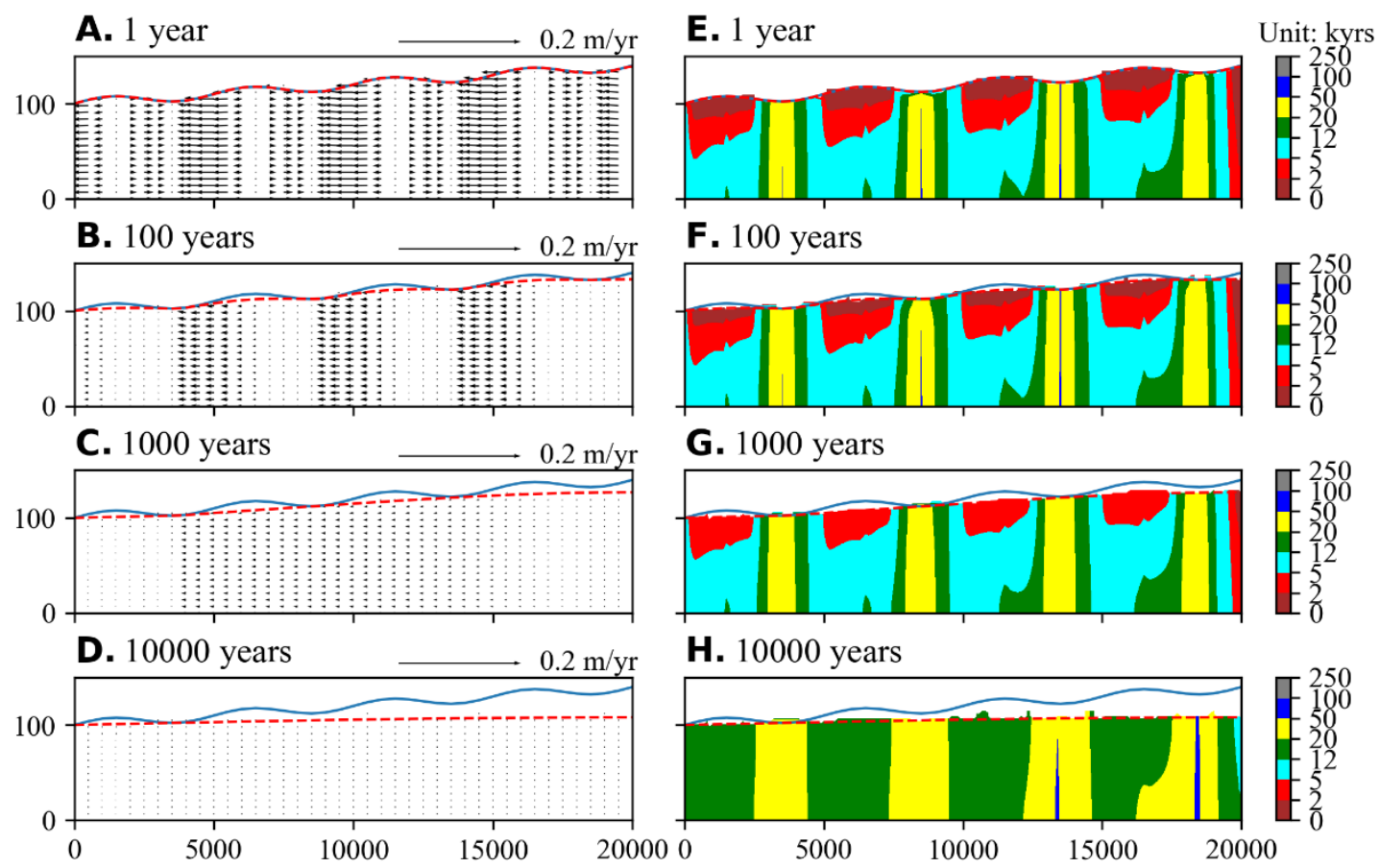

Figure S5. Temporal variation in groundwater flow and groundwater age corresponding to Figure 2D1 and 2D2, respectively. The aquifer setting is the same as the base case except that the topographic amplitude $a$ was changed from $50 \mathrm{~m}$ to $5 \mathrm{~m}$, the slope $\tan \tau$ was changed from 0.02 to 0.002 and the thickness $z_{0}$ was varied from $1,000 \mathrm{~m}$ to $100 \mathrm{~m}$. 


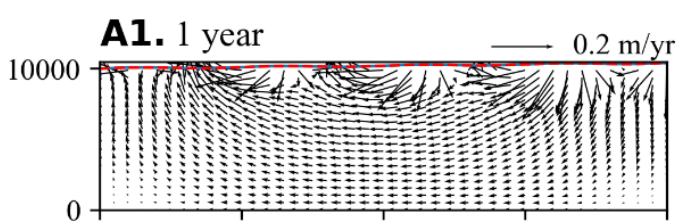

B1. 100 years

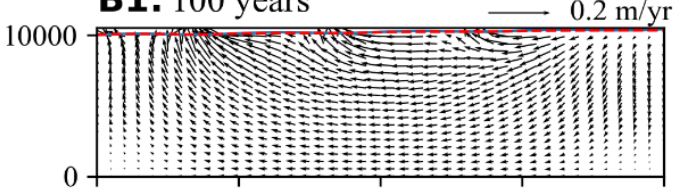

C1. 1000 years

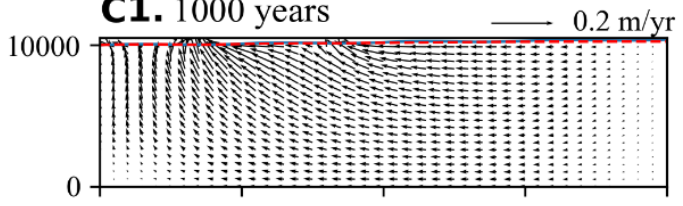

D1. 10000 years

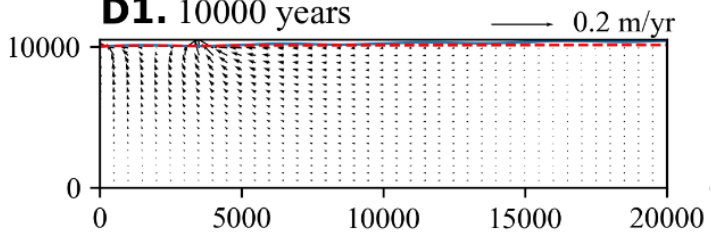

A2. 1 year

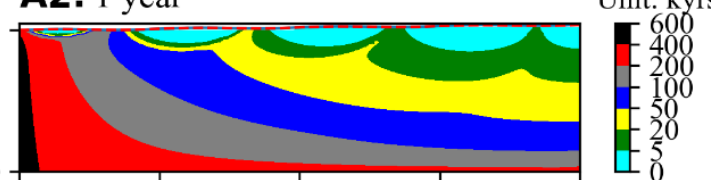

B2. 100 years

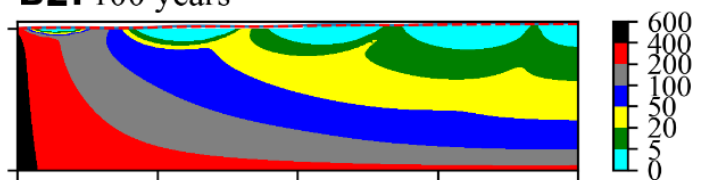

C2. 1000 years

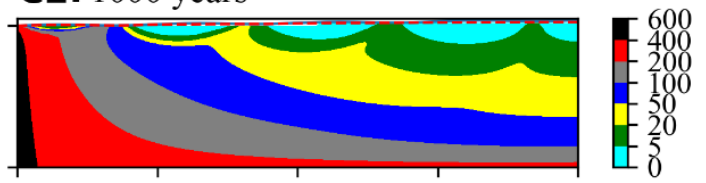

D2. 10000 years

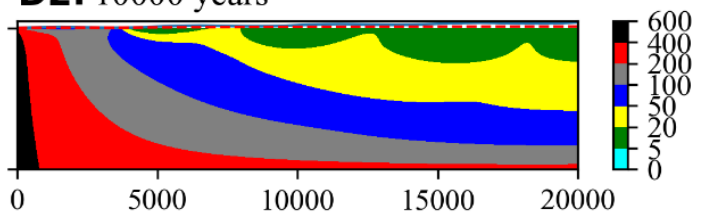

Figure S6. Temporal variation in groundwater flow and groundwater age corresponding to Figure

2E1 and 2E2, respectively. The aquifer setting is the same as the base case except that the thickness $z_{0}$ was varied from $1,000 \mathrm{~m}$ to $10,000 \mathrm{~m}$. This model is frequently seen in hydrogeology textbooks (e.g., Freeze and Cheery, 1979). Note that 10,000m thickness is a bit nonphysical. It was used to conduct mathematic sensitivity to demonstrate the age persistence from a mathematical viewpoint.

Apart from the sensitivity analysis shown in Figure 3 of the main text, more sensitivity analysis (Models 5 to 7) was conducted as shown in Figure S7 (relevant main parameters are shown in Table S2). For example, a typical sandy aquifer is usually characterized with hydraulic conductivity $(K)$ at approximately $10^{-7} \sim 10^{-4} \mathrm{~m} / \mathrm{s}$ or $0.009 \sim 8.64 \mathrm{~m} / \mathrm{d}$ (Freeze and Cherry, 1979). As the transport of water particles is directly proportional to groundwater flow rate through advection and dispersion, an increase in $K$ will lead to relatively faster groundwater flow and so the reduced gradient of the water table and faster migration of the age pattern downstream after 
10,000 years (Figure S7B \& Figure S8). $K$ might exponentially decay in the vertical direction. This will result in persistence not only in the age pattern but also flow systems (Figure S7C \& Figure S9). A greater hydrodynamic dispersivity (quantifying mixing at pore-scale flowpaths) will lead to stronger smearing of the age pattern, making age range narrower and also flattening age contours (Figure S7D \& Figure S10). Despite these factors, the groundwater age still resembles its original pattern at the start of the Holocene period after 10,000 years.
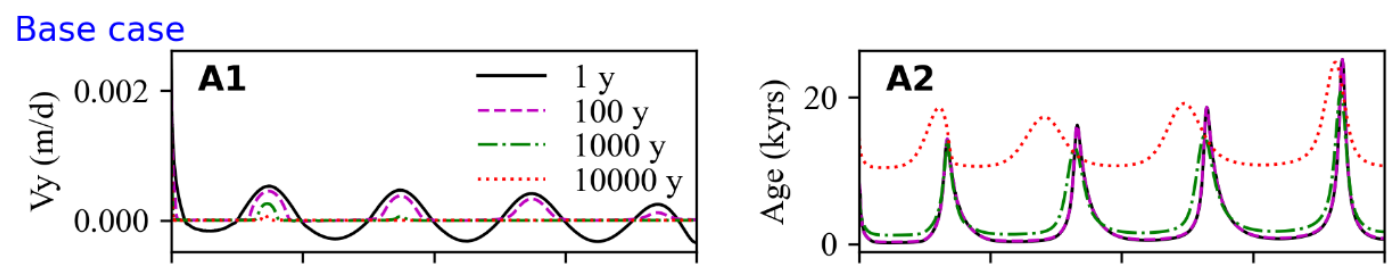

\section{Model 5}
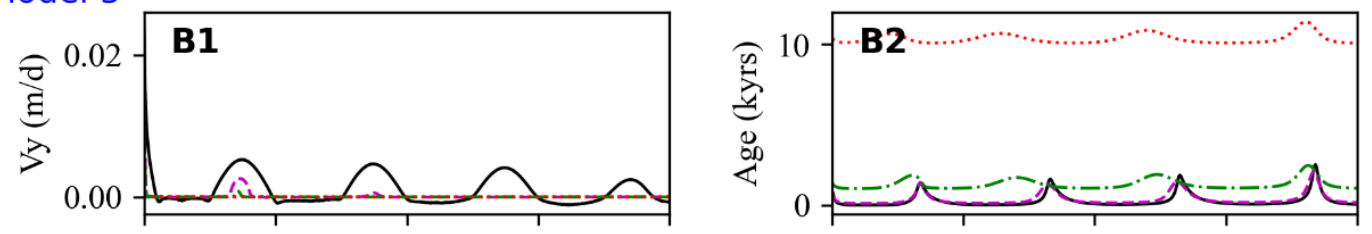

\section{Model 6}
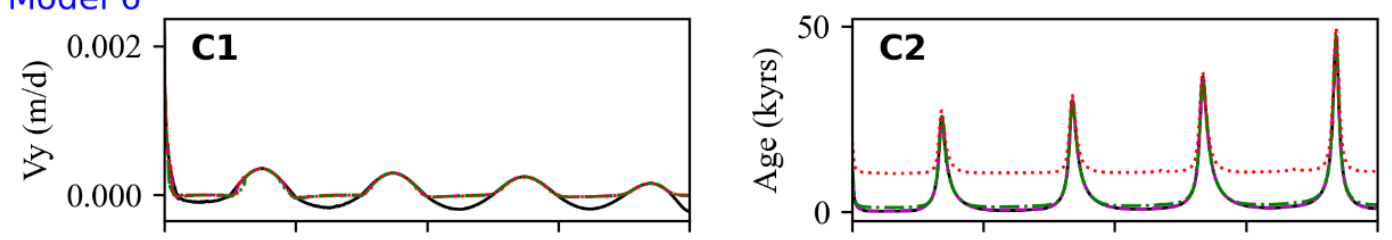

Model 7


Figure S7. Spatial variation in vertical fluxes (Vy) and groundwater age for four different times at the elevation of 1,000 m. Base case: results from the base case shown in Figure 1 in the main text (also same as Figure 2A); Model 5: same as the base case except that the hydraulic conductivity $\mathbf{K}$ was increased from $0.01 \mathrm{~m} / \mathrm{d}$ to $0.1 \mathrm{~m} / \mathrm{d}$; Model 6: same as the base case except the hydraulic 
conductivity $\mathbf{K}$ decreases in an exponential manner; Model 7: same as the base case except that the longitudinal hydrodynamic dispersivity $\mathrm{D}_{\mathrm{L}}$ was decreased from $100 \mathrm{~m}$ to $10 \mathrm{~m}$. Detailed flow field and age pattern of Models 5-7 are shown in Figures S8-S10.
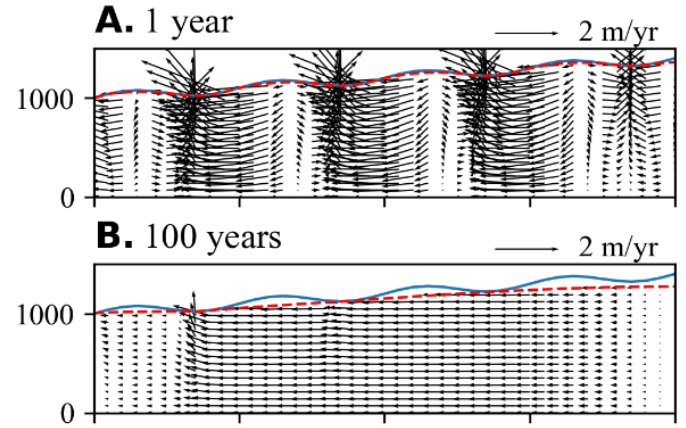

C. 1000 years
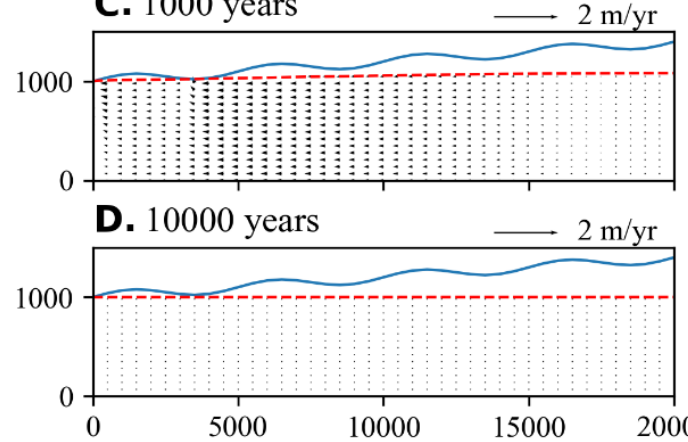

E. 1 year

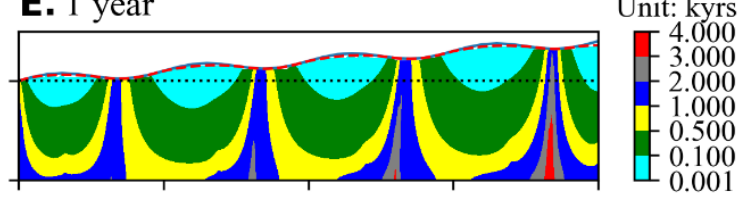

F. 100 years

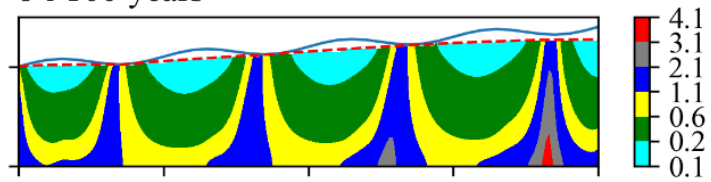

G. 1000 years

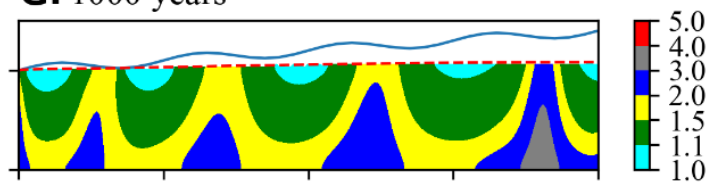

H. 10000 years

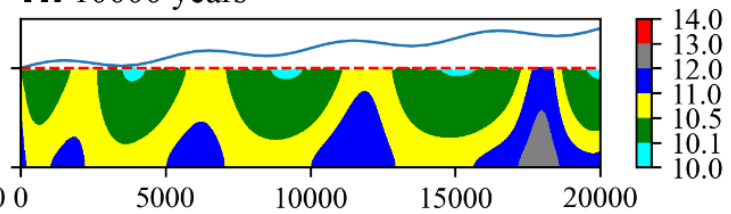

Figure S8. Temporal variation in groundwater flow and groundwater age corresponding to Figure

S7B1 and S7B2, respectively.

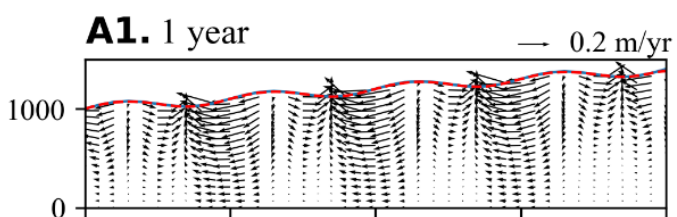

B1. 100 years
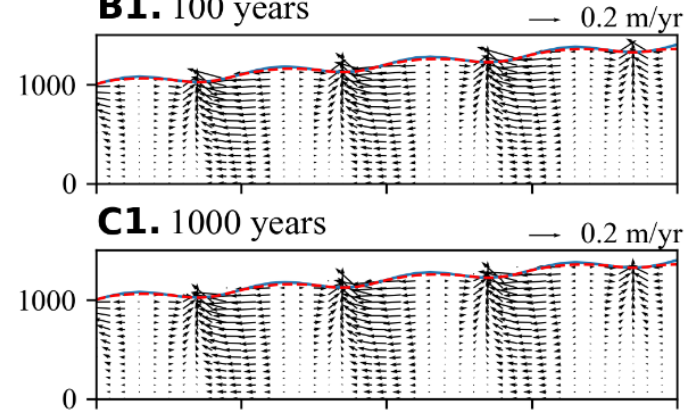

D1. 10000 years

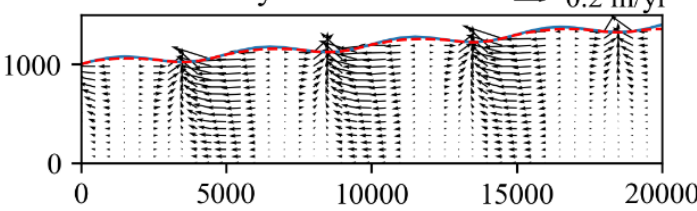

A2. 1 year



B2. 100 years

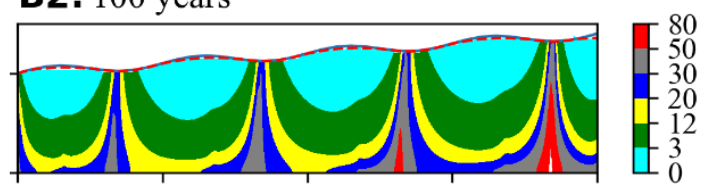

C2. 1000 years

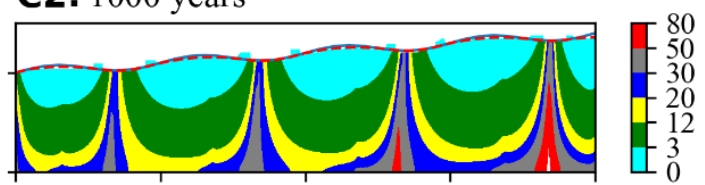

D2. 10000 years




Figure S9. Temporal variation in groundwater flow and groundwater age corresponding to Figure S7C1 and S7C2, respectively.
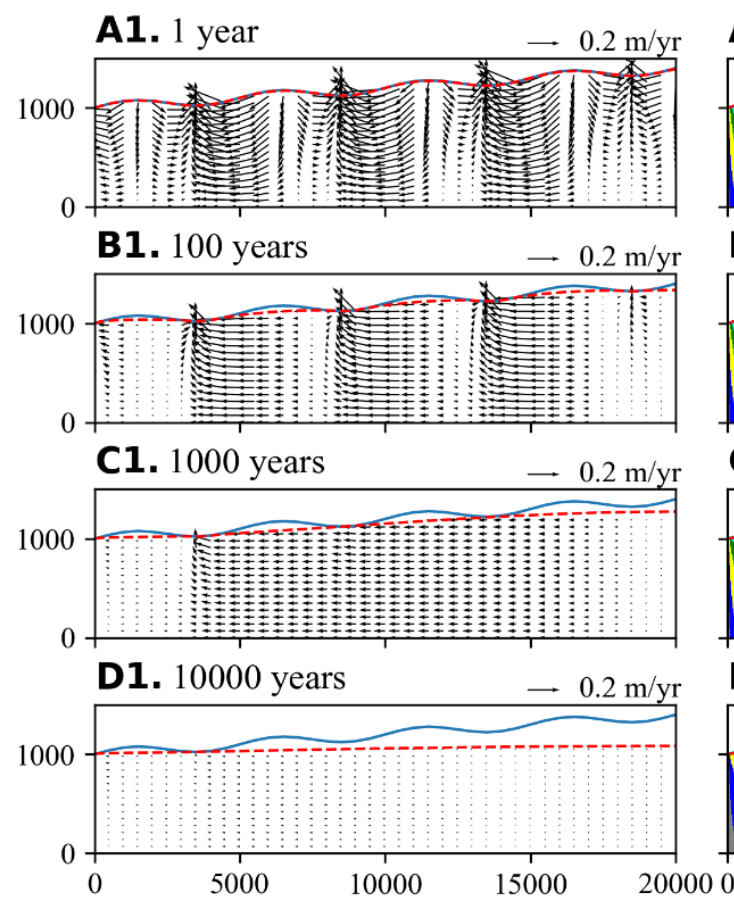

A2. 1 year

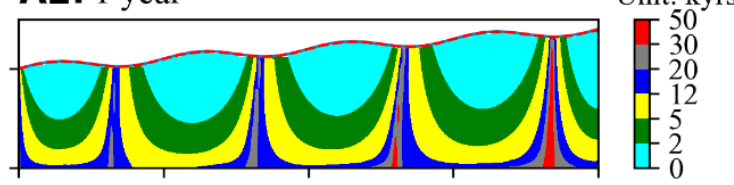

B2. 100 years

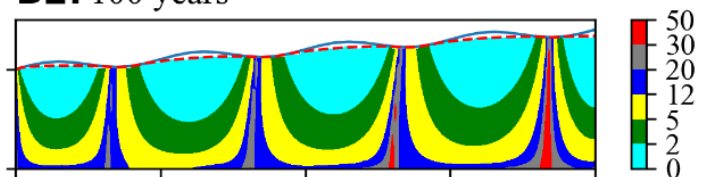

C2. 1000 years

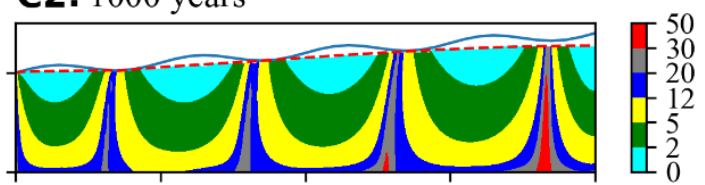

D2. 10000 years

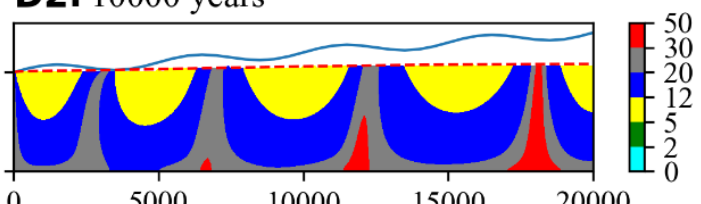

Figure S10. Temporal variation in groundwater flow and groundwater age corresponding to Figure S7D1 and S7D2, respectively.

\section{References}

Carsel, R.F., and Parrish, R.S., 1988, Developing joint probability distributions of soil water retention characteristics: Water Resources Research, v. 24, p. 755-769.

Diersch, H.-J., 2013. FEFLOW: Finite Element Modeling of Flow, Mass and Heat Transport in Porous and Fractured Media. Springer Science \& Business Media.

Freeze, R.A., Cheery, J.A., 1979, Groundwater, Prentice Hall, Englewood Cliffs, NJ.

Goode, D., 1996, Direct simulation of groundwater age: Water Resources Research, v. 32, p. 289296. 
Rousseau-Gueutin, P., Love, A.J., Vasseur, G., Robinson, N.I., Simmons, C.T., and De Marsily, G., 2013, Time to reach near-steady state in large aquifers: Water Resources Research, v. 49, p. $6893-6908$.

Robinson, N.I., and Love, A.J., 2013, Hidden channels of groundwater flow in Tóthian drainage basins: Advances in Water Resources, v.62, p. 71-78.

Schulze-Makuch, D., 2005, Longitudinal dispersivity data and implications for scaling behavior: Ground Water, v. 43, p. 443-456.

Tóth, J., 1963, A theoretical analysis of groundwater flow in small drainage basins: Journal of Geophysical Research, v. 68(16), p. 4795-4812.

Tóth, J., 2009, Gravitational Systems of Groundwater Flow (Theory, Evaluation, Utilization), Cambridge University Press, 297 p. 